\title{
Car phones fuel battle
}

\section{Tokyo \& Washington}

IN line with tough new trade legislation, the United States last week released a 'hit list' of 54 Japanese high-technology products targeted for possible sanctions because of Japan's refusal to open fully its telecommunications markets. Additional sanctions may follow because of Japan's failure to import other US high technology products, including supercomputers, semiconductors and satellites.

Frustration in Congress over Japan's reluctance to buy US products continues to increase. The Omnibus Trade and Competitiveness Act of 1988 placed new requirements on the Office of the US Trade Representative to provide a clear picture of why US products were not selling better abroad. At the end of last month, the office released two reports that indicate rocky times for US-Japan trade relations.

The review of telecommunications agreements concludes that Japan has violated the MOSS (Market Oriented Sector Specific) agreements of the mid-1980s by limiting access of a car telephone system developed by the US company Motorola. Under US pressure, Japan's Ministry of Post and Telecommunications allowed the Motorola system into Japan, but only in the western part of the country. Eastern Japan, which includes Tokyo and Nagoya and comprises 70 per cent of the cartelephone market, is reserved for a competing system developed by the domestic telecommunications giant Nippon Telegraph and Telephone Corporation (NTT).

Furthermore, whereas the NTT system is allowed to 'roam' into western Japan using alternative radio frequencies, the ministry has refused to allot such frequencies to the Motorola system in the Nagoya-Tokyo area.

The annual report on trade barriers covers dozens of countries and a complete spectrum of trade from sales of US supercomputers in Japan to barriers to US exports of apples to Norway. But Japan takes up more pages than any other country and most of the trade problems with Japan involve high technology. The report will be used by the US trade office to designate 'priority countries' that will be subject to investigations that could lead to sanctions. The countries will be selected by the end of this month and Japan is again expected to be included.

Many US high-technology products that sell well elsewhere in the world have failed to penetrate the Japanese market, according to the report. The US opticalfibre cable industry, which the report says is among the world's most competitive, has managed to capture only 3 per cent of Japan's $\$ 500$ million-a-year market.

Similarly, sales of US telecommunica- tions satellites have been meagre. A few satellites have been sold to private telecom companies that have tie-ups with US companies. But NTT, Japan's biggest telecommunications company, is obliged to buy more expensive Japanese satellites because the government, the major shareholder in NTT, wants to nurture the domestic satellite industry.

The United States is particularly dissatisified with the failure of Japan's universities and government research institutes to buy US supercomputers, a technology in which the United States is the acknowledged world leader although Japanese manufacturers are not far behind. A 1987 bilateral agreement was intended to simplify public procurement of US supercomputers. But only two machines have been sold, and those were bought under a special import promotion plan on a non-competitive basis.

Semiconductor trade is an arena in which the United States has been mauled by Japan. But the United States continues to lead the world in development of many types of advanced microchips and microprocessors. The report criticizes Japan for failing to increase access of US chips to the Japanese market as agreed under the 1986 US-Japan Semiconductor Agreement.

TRON (The Real Time Operating System Nucleus), a new 'open architecture' for computers invented by Ken
Sakamura of Tokyo Univeristy, is a newcomer to US-Japan trade disputes. Although no commercial TRON computer is yet available, a council set up by the Ministry of Education, Science and Culture (MESC) to recommmend computers for high schools has laid down specifications that favour TRON operating systems. Furthermore, NTT announced in January that it will require TRON architecture for its next-generation digital communications network.

The US trade office's report on trade barriers expects that US computer operating systems (such as MS-DOS and UNIX) will be effectively excluded from MESC's lucrative $\$ 7,000$ million procurement of computers for high schools. Looking further to the future, there are US fears that Japanese manufacturers will 'design in' TRON microprocessors and 'design out' US parts, thereby further aggravating the semiconductor dispute.

Coincident with release of the two reports, planeloads of Japanese government officials arrived in Washington to try to head off US retaliation. Japan's viceminister of post and telecommunications, Yusai Okuyama, offered Motorola access to the whole of Japan for the next generation of digital car telephones and Hiroshi Mitsuzuka, minister of international trade and industry, promised to increase public sector procurement of US supercomputers. Further Japanese concessions are expected before the end of the month.

David Swinbanks \& Joseph Palca US OBSERVATORIES

\section{University of Arizona construction agreed}

\section{Tucson}

DESPITE demonstrations and a 350-page appeal from an environmental and conservation group, the US Forest Service has approved the University of Arizona management plan for a new observatory in southeastern Arizona. Last month, the Forest Service issued a special-use permit authorizing construction of three telescopes, support facilities and an access road on Mount Graham, a 10,700-foot peak that is also home to an endangered species of red squirrel.

Last November, Congress passed a bill authorizing the observatory (see Nature 335,$755 ; 1988$ ) with the understanding that measures outlined in a US Fish and Wildlife Biological Opinion to protect the squirrel were followed. The Mount Graham Conservation Project and Earth First! Biodiversity Project submitted a 350-page appeal challenging that opinion and the Forest Service assessment of the observatory's environmental impact. The group had requested a stay on the specialuse permit until the appeal was considered. According to the project coordinator, Jasper Carlton, the opinion is inconsistent with the Endangered Species Act, and the university's management plan is inconsistent with the opinion.

However, the Forest Service refused that request. "Congress has not given us a whole lot of options", says Pat Jackson, appeals and litigation officer for the regional office of the Forest Service in Albuquerque, New Mexico. Now that federal law incorporates the observatory plan in the biological opinion, the Forest Service must carry it out. "We don't feel that anything inappropriate has been done." As part of the management plan, which was developed by the university and the Forest Service, biologists will begin a 10-year study of the squirrel and will monitor the squirrels close to the construction site. A squirrel refuge is being established, roads near important habitats will be closed and areas will be reforested. Three telescopes will be built initially and four more are planned, depending on the effects on the endangered squirrel.

Last month, protesters from Earth First! and the Sierra Club demonstrated at the university and at Mount Graham.

Elizabeth Pennisi 